\title{
Study of Outcome of Vaginal Birth after Caesarean Section
}

\author{
${ }^{1}$ Dr Sukun B Mehta, ${ }^{2}$ Dr Megha S Patel, ${ }^{3}$ Dr Purvi M Parikh
}

\begin{abstract}
The study was conducted in the tertiary care hospital, describing the outcome in the vaginal birth after previous one caesarean section.

A retrospective study was carried out from $1^{\text {st }}$ July 2014 to $30^{\text {th }}$ November 2015 on 30 women with previous one Lower segment caesarean section (LSCS). Women having medical or obstetric complication were excluded. An informed and written consent was taken for trial of scar for vaginal delivery. Spontaneous onset of labor was awaited up to 40 weeks. Induction of labor was considered in highly selected cases. Progress of labor was constantly supervised by maintaining partograph and monitoring fetal well being by Non Stress test (NST).

Out of the 30 women enrolled in the study, 20(66.7\%) women underwent emergency caesarean section, 10(33.3\%) women underwent successful vaginal delivery. Most common cause for repeat caesarean section was Scar tenderness (50\%). 10 women out of 30 were induced, out of that 7 underwent repeat emergency caesarean section, 3 delivered vaginally. During this study most common maternal complication was scar dehiscence (33.3\%) and one baby was admitted in NICU for respiratory distress.
\end{abstract}

Keywords: vaginal delivery after cesarean birth, previous cesarean section.

\section{Introduction}

Caesarean section is the most commonly performed surgery nowadays. Starting from 2000 BC when CS was performed to deliver the fetus from a dead or dying mother. Today the incidence of Caesarean birth is rising from about $5 \%$ to more than $20 \%$. Initially for these increasing caesarean deliveries, the future pregnancies would nearly always be managed by repeat CS due to fear of uterine rupture. But now the dictum "Once a caesarean, always caesarean" is challenged. It is now changed to "Once a caesarean delivery, always a hospital delivery." Now with proper patient selection, continuous fetal monitoring, early diagnosis and intervention for uterine rupture; safe vaginal delivery in a woman having previous caesarean delivery is being tried. By this, rate of caesarean delivery can be reduced. This will reduce expenses, hospital stay, operative morbidity and mortality. The purpose of this study was to evaluate the efficacy and safety of VBAC.

\section{Materials And Methods}

A retrospective study was carried out on 30 women (booked or emergency cases) with previous one caesarean section, from $1^{\text {st }}$ July 2014 to $30^{\text {th }}$ November 2015.

\section{The following cases were excluded from the study-}

1. Previous Classical caesarean section

2. Estimated fetal weight $>3.5 \mathrm{~kg}$

3. Breech presentation or Transverse lie

4. Contraindication to vaginal birth like Cephalopelvic disproportion, major degree placenta praevia

5. Associated medical or obstetric complications like preterm, anemia, PIH, diabetes, heart disease etc.

6. Unfavorable cervix with poor Bishop's score

7. Twin pregnancy

8. Previous CS before $<18$ month

All women were admitted if they went into spontaneous labor. Those women whose labor were not spontaneous, were induced depending on Bishop's score. Induction was started with 2.5 unit Oxytocin in $500 \mathrm{ml}$ of Ringer Lactate solution starting at 6 to 8 drops per minute. Rate was gradually increased to get 3-4 contractions every 10 minutes each lasting for $40-45$ seconds. Whether the labor was induced or spontaneous it was monitored with

- Hourly recording of maternal vital parameters-temperature, pulse blood pressure, respiration

- Monitoring uterine contraction

- Fetal monitoring with auscultation of fetal heart sound with stethoscope and Non stress test(NST)

- A close watch for the early recognition for scar dehiscence and rupture by identifying maternal tachycardia, vaginal bleeding, scar tenderness and fetal heart rate alterations.

- Partograph 
Attempt at vaginal delivery was abandoned if there was any suspicion of scar dehiscence, scar rupture, fetal distress or non progression of labor. Facilities for emergency caesarean section were kept ready.

\section{Results}

Table 1: Outcome of trial of scar $(n=30)$

\begin{tabular}{|l|l|l|}
\hline & Outcome of Trial & No. of cases \\
\hline 1 & Delivered vaginally & $10(33.3 \%)$ \\
\hline 2 & Underwent Caesarean section & $20(66.7 \%)$ \\
\hline & & 30 \\
\hline
\end{tabular}

Table 2: Indications For Emergency Caesarean Section $(\mathrm{N}=20)$

\begin{tabular}{|l|l|l|}
\hline & \multicolumn{1}{|c|}{ Indication } & \multicolumn{1}{c|}{ Cases } \\
\hline $\mathbf{1}$ & Scar tenderness & $10(50 \%)$ \\
\hline $\mathbf{2}$ & Fetal distress and MSL & $6(30 \%)$ \\
\hline $\mathbf{3}$ & Non progression of labor & $3(15 \%)$ \\
\hline $\mathbf{4}$ & Uterine rupture & $1(5 \%)$ \\
\hline & & $\mathbf{2 0}$ \\
\hline
\end{tabular}

Table 3: Outcome of induction of labor in case of VBAC $(n=10)$

\begin{tabular}{|c|l|c|}
\hline & MODE OF DELIVERY & CASES \\
\hline $\mathbf{1}$ & Vaginal delivery & $3(30 \%)$ \\
\hline $\mathbf{2}$ & Emergency CS & $7(70 \%)$ \\
\hline & & $\mathbf{1 0}$ \\
\hline
\end{tabular}

Table 4. Indications of repeat Caesarean section in case of induction $(n=7)$

\begin{tabular}{|c|l|c|}
\hline & \multicolumn{1}{|c|}{ INDICATION } & CASES \\
\hline $\mathbf{1}$ & Scar tenderness & $3(30 \%)$ \\
\hline $\mathbf{2}$ & Fetal distress & $2(20 \%)$ \\
\hline $\mathbf{3}$ & Non progression of labor & $1(10 \%)$ \\
\hline $\mathbf{4}$ & Uterine rupture & $1(10 \%)$ \\
\hline & & $\mathbf{7}$ \\
\hline
\end{tabular}

Table 5. Maternal and Neonatal complications $(\mathrm{N}=30)$

\begin{tabular}{|l|l|l|}
\hline & Maternal complication & Cases \\
\hline 1 & Scar dehiscence & $10(33.3 \%)$ \\
\hline 2 & Cervical tear & $3(10 \%)$ \\
\hline 3 & PPH & $2(6.67 \%)$ \\
\hline 4 & Manual removal of placenta & $2(6.67 \%)$ \\
\hline 5 & Uterine rupture & $1(3.3 \%)$ \\
\hline & & $18(60 \%)$ \\
\hline
\end{tabular}

\begin{tabular}{|l|l|l|}
\hline & NEONATAL COMPLICATION & CASES \\
\hline 1 & Still birth & $1(3.3 \%)$ \\
\hline 2 & NICU Admission & $1(3.3 \%)$ \\
\hline & & 2 \\
\hline
\end{tabular}

\section{Discussion}

Perinatal risk is more after a failed trial of labor compared to successful vaginal delivery in case of VBAC (Rossi, 2008 and Babbar 2013). The woman must be given all the important information and she should be given choice for the mode of delivery in case of previous caesarean birth.

The main objective of this study was to evaluate safety and success rate of attempting VBAC, in a tertiary care center, after one previous caesarean birth.The selection of woman was influenced by desire of woman and condition favorable for vaginal delivery. Out of 30 women enrolled in the study 20(66.7\%) underwent emergency caesarean section and 10(33.3\%) delivered spontaneously. Table 1 shows this result. Indications for previous caesarean section in these 30 women were fetal distress in 10(33.3\%), Malpresentation in $6(20 \%)$, Premature rupture of membranes with non progress of labor in 5(16.5\%), severe oligohydramnious in $3(10 \%)$, severe PIH in $3(10 \%)$, placenta praevia in $2(6.9 \%)$ and cord prolapse in $1(3.3 \%)$. This result is comparable with study Foureur et al,2010 which showed $25-30 \%$ of successful vaginal delivery in the cases of previous LSCS and 70-75\% underwent emergency LSCS.

Table 2 shows indications for emergency LSCS. Most common indication was scar tenderness (50\%). There were $30 \%$ cases of fetal distress and $15 \%$ emergency CS was taken for non progression of labor. There was one case of uterine rupture. Study of RANZCOG,2010 support this showing $0.5-7 \%$ chances of rupture. 
The rate of rupture increases in the cases in which induction was done. So in this study induction was not done upto 40weeks. After proper assessment of cervix with Bishop's score, induction was tried. According to ACOG,2013a misoprostol was avoided for induction. 10 out of 30 cases were induced. As per Table 3 out of which $3(30 \%)$ underwent successful vaginal delivery and 7(70\%) underwent emergency CS. Table 4 shows that $3 / 7(30 \%)$ developed scar tenderness, 2 (20\%) developed fetal distress and 1(10\%) had rupture. Grobman, 2007a shows fourfold higher risk of rupture with induction compared to spontaneous labor. Cahill and coworkers (2008) and Goetzl and associates(2001) show dose related risk of rupture with oxytocin.

Table 5 shows fetomaternal complications during trial.10 (33.3\%)had scar dehiscence (stanhope,2013),3 (10\%) had cervical tear,2(6.67\%) had PPH and 2(6.67\%) had manual removal of placenta. There was one still born baby (3.3\%) and one baby was admitted in NICU for fetal distress.Guise,2010 shows higher rate of hypoxic ischemic encephalopathy and neonatal mortality during trial. In our study emergency CS was taken to reduce fetal morbidity at early sign of fetal distress.

There are few high quality data available to guide prope selection of labor candidates in case of trial of scar in VBAC(Guise 2004; Hashima, 2004) Proper case selection will increase success rate and reduce the complications.( Gregory, 2008) .The maternal complications and perinatal morbidity in the present study are identical to those seen with other normal vaginal deliveries with the exception of risk of scar dehiscence. An attempt for VBAC is well justified for caesarean pregnancies with nonrecurrent indications. Screening for this should preferably begin at antenatal booking itself to minimize the associated risks. Proper selection, appropriate timing and suitable method of induction with close monitoring are the key factors to achieve great degree of success.

\section{References}

[1]. Dutta DC. Vaginal birth in previous CS in Konar H (Eds), Text book of obstetrics,8th Edition, 2015

[2]. Williams obstetrics, vaginal birth in prior caesarean delivery, $24^{\text {th }}$ edition, 2014

[3]. Ian donald's practical obstetric problems, vaginal delivery in previous caesarean section, $17^{\text {th }}$ edition, 2015

[4]. Hamilton BE, Martin JA, Ventura SJ. Births: Preliminary data for 2010. Natl Vital Stat Rep. 2011. [January 9, 2012].

[5]. Martin JA, Hamilton BE, Sutton PD, et al. Births: Final data for 2007. Natl Vital Stat Rep. 2010.

[6]. National Institutes of Health Consensus Development Conference Statement. Vaginal Birth After Cesarean: New Insights, March 810, 2010. Obstet Gynecol. 2010 Jun;115(6):1279-95.

[7]. McMahon M, Luther E, Bowes W, et al. Comparison of a trial of labor with an elective second cesarean section. N Engl J Med. 1996;335(10):689-95.

[8]. Guise JM, Eden K, Emeis C, et al. Vaginal birth after cesarean: new insights. Evid Rep Technol Assess (Full Rep) 2010 Mar;(191):1-397.

[9]. Caron A, Neuhauser D. The effect of public accountability on hospital performance: trends in rates for cesarean sections and vaginal births after cesarean section in Cleveland, Ohio. Qual Manag Health Care. 1999;7(2):1-10

[10]. Macones GA. Clinical outcomes in VBAC attempts: what to say to patients? Am J Obstet Gynecol. 2008 Jul;199(1):1-2

[11]. Royal College of Obstetricians and Gynaecologists. Birth After Previous Caesarean Birth. Green-top Guideline No. 45. London: RCOG; 2007

[12]. National Institute for Health and Clinical Excellence. Caesarean section. NICE clinical guideline 132. Manchester: NICE; 2011.

[13]. American College of Obstetricians and Gynecologists. ACOG Practice bulletin no. 115: Vaginal birth after previous cesarean delivery. Obstet Gynecol 2010;116:450-63.

[14]. Marshall NE, Fu R, Guise JM. Impact of multiple cesarean deliveries on maternal morbidity: a systematic review. Am J Obstet Gynecol 2011;205:262.

[15]. American College of Obstetricians and Gynecologists. ACOG Practice bulletin no. 115: Vaginal birth after previous cesarean delivery. Obstet Gynecol 2010;116:450-63. 